\title{
Health-related quality of life in a multidomain intervention trial to prevent cognitive decline (FINGER)
}

\section{Strandberg, T.}

2017-04

Strandberg , T , Levalahti , E , Ngandu , T , Solomon , A , Kivipelto , M , Lehtisalo , J , Laatikainen, $T$, Soininen, $H$, Antikainen , R , Jula , A, Tuomilehto , J , Peltonen , M , Lindstrom , J, Rauramaa , R, Pajala , S , Hanninen , T, Solomon , A , Paajanen , T, Mangialasche , F \& FINGER Study Grp 2017 , ' Health-related quality of life in a multidomain intervention trial to prevent cognitive decline (FINGER) ' , European Geriatric Medicine , vol. 8 , no. 2 , pp. 164-167 . https://doi.org/10.1016/j.eurger.2016.12.005

http://hdl.handle.net/10138/235592

https://doi.org/10.1016/j.eurger.2016.12.005

unspecified

publishedVersion

Downloaded from Helda, University of Helsinki institutional repository.

This is an electronic reprint of the original article.

This reprint may differ from the original in pagination and typographic detail.

Please cite the original version. 


\title{
Research paper
}

\section{Health-related quality of life in a multidomain intervention trial to prevent cognitive decline (FINGER)}

\author{
T.E. Strandberg ${ }^{\mathrm{a}, \mathrm{b}, *}$, E. Levälahti ${ }^{\mathrm{c}}$, T. Ngandu $^{\mathrm{c}, \mathrm{d}}$, A. Solomon ${ }^{\mathrm{d}, \mathrm{e}, \mathrm{f}}$, M. Kivipelto ${ }^{\mathrm{c}, \mathrm{d}, \mathrm{e}, \mathrm{f}}$ \\ for the FINGER Study Group, M. Kivipelto ${ }^{1,3}$, T. Ngandu $^{2,12}$, J. Lehtisalo ${ }^{2,10}$, T. Laatikainen ${ }^{4}$, \\ H. Soininen ${ }^{5}$, T. Strandberg ${ }^{6,13}$, R. Antikainen ${ }^{6,13}$, A. Jula ${ }^{7}$, J. Tuomilehto ${ }^{8,13}$, M. Peltonen ${ }^{9}$, \\ E. Levälahti ${ }^{9}$, J. Lindström ${ }^{10}$, R. Rauramaa ${ }^{11}$, S. Pajala ${ }^{11}$, T. Hänninen ${ }^{12}$, A. Solomon ${ }^{14}$, \\ T. Paajanen ${ }^{14}, \mathrm{~F}$. Mangialasche ${ }^{14}$
}

${ }^{a}$ University of Helsinki, Helsinki University Hospital, Helsinki, Finland

${ }^{\mathrm{b}}$ Centre for Life Course Health Research, University of Oulu, Oulu, Finland

${ }^{\text {c } C h r o n i c ~ D i s e a s e ~ P r e v e n t i o n ~ U n i t, ~ N a t i o n a l ~ I n s t i t u t e ~ f o r ~ H e a l t h ~ a n d ~ W e l f a r e, ~ H e l s i n k i, ~ F i n l a n d ~}$

d Division of Clinical Geriatrics, Center for Alzheimer Research, NVS, Karolinska Institutet, Stockholm, Sweden

e Institute of Clinical Medicine/Neurology, University of Eastern Finland, Kuopio, Finland

${ }^{\mathrm{f}}$ Aging Research Center, Karolinska Institutet, Stockholm, Sweden

\section{A R T I C L E I N F O}

\section{Article history:}

Received 19 October 2016

Accepted 27 December 2016

Available online 24 January 2017

\section{Keywords:}

Cognition

Prevention

Multidomain

Health-related quality of life

RAND-36

SF-36

\begin{abstract}
A B S T R A C T
Introduction: The Finnish Geriatric Intervention Study to Prevent Cognitive Impairment and Disability (FINGER) successfully demonstrated that multidomain lifestyle intervention can improve or maintain cognitive functioning in at-risk individuals. Health-related quality of life (HRQLL) was a secondary endpoint.

Methods: The intervention ( $n=631)$ aimed at healthy diet, increased physical activity, cognitive training, and vascular risk management. The control group $(n=629)$ was given general health advice. HRQoL was assessed at baseline, 12, and 24 months using validated RAND-36 (SF-36) instrument with 8 scales. Results: During the 2-year intervention period, mean scores in all scales decreased in the control group, but increased in the intervention group for vitality (12 months), social function (12 months), and especially general health at both 12 and 24 months. There was a statistically significant beneficial effect of intervention on the change in general health and physical function at 12 and 24 months. Conclusion: Multidomain lifestyle intervention improved also important dimensions of HRQoL.
\end{abstract}

(c) 2017 Elsevier Masson SAS and European Union Geriatric Medicine Society. All rights reserved.

\footnotetext{
1 Main investigator.

2 Coordination.

3 Sub-cohort leaders (Helsinki cohort).

${ }^{4}$ Sub-cohort leaders (Vantaa cohort).

5 Sub-cohort leaders (Kuopio cohort).

6 Sub-cohort leaders (Oulu cohort).

7 Sub-cohort leaders (Turku cohort).

8 Sub-cohort leaders (Seinäjoki cohort).

9 Statistical analyses.

${ }^{10}$ Intervention supervision (nutrition component).

11 Intervention supervision (physical exercise component).

12 Intervention supervision (cognitive component).

13 Intervention supervision (vascular risk factor component).

14 Other study members and collaborators.

* Corresponding author. University of Helsinki, PO Box 340, FIN-00029 Helsinki, Finland. Tel.: +358 405969285

E-mail address: timo.strandberg@oulu.fi (T.E. Strandberg).
}

\section{Introduction}

The Finnish Geriatric Intervention Study to Prevent Cognitive Impairment and Disability (FINGER) is a "proof-of-concept" double-blind, randomized controlled trial, which successfully demonstrated that a 2-year multidomain lifestyle intervention - consisting of exercise, dietary counselling, cognitive training, and cardiovascular risk factor control - can improve or maintain cognitive functioning in older persons at risk of cognitive decline [1]. A further beneficial dimension of the intervention would be its potential effect on health-related quality of life (HRQoL), a clinically important endpoint in outcome research in older people [2]. An improvement in HRQoL could provide added value, and analysis of HRQoL might also help to discern efficient parts of the multidomain intervention. We report here the in-trial changes of HRQoL in the intervention and control groups. 


\section{Methods}

The FINGER study is registered at Clinicaltrials.gov (NCT01041989). FINGER participants were recruited from earlier population-based surveys in Finland, and inclusion criteria were Cardiovascular Risk Factors, Aging and Dementia (CAIDE) Dementia Risk Score at least 6 points and their cognition average or slightly lower than expected for age. Between Sept 7, 2009, and Nov 24, 2011, 2654 individuals were screened and 1260 community-dwelling individuals aged 60 to 77 years were randomly assigned to intervention $(n=631)$ and control $(n=629)$ groups [1]. The two-year intervention aimed at healthy diet, increased physical activity, cognitive training, and evidence-based vascular risk management and monitoring. The control group was given general health advice.

Study participants were not actively told of their group allocation, and the assessors of study outcomes were blinded to group allocation. Analysis was by modified intention to treat (all participants with at least one post-baseline observation). The primary outcome was cognitive performance, change in cognition measured with comprehensive neuropsychological test battery (NTB) Z score, and the results showed a statistically significant between-group difference in the change of NTB total score per year (0.022, 95\% CI: $0.002-0.042, P=0.030$ [1]). NTB was selected because a sensitive cognitive test was required in this population with MMSE $\geq 26$ points at baseline.

HRQoL was a pre-specified secondary outcome, and it was measured using the RAND-36 (Medical Outcomes Study 36-Item Short-Form Health Survey; practically identical to Short Form [SF]36) with its 8 scales: Physical Function (PF), Role Physical (RP), Role mental (RM), Vitality (VT), Mental Health (MH), Social Function (SF), Bodily Pain (BP), and General Health (GH) [3]. HRQoL assessments were performed at baseline, 12, and 24 months. The results of RAND-36 have been validated in the Finnish population, and population standards for the 8 scales are available [4].

\section{Statistical analysis}

Mplus (Version 5) was used for fitting Growth mixture models (GMM) with robust maximum likelihood estimation method. Logit link was used to analyze the relationships between categorized scales (RP, RM, SF) and latent growth factors. GMMs are more complex than mixed models used in the cognition report of FINGER [1], since they are based on mixtures of distributions to handle large discrepancies from normal distribution. Estimation of separate mixture distributions is based on latent class analysis in which, as a first step, models with different number of latent classes are estimated (here models with 1-5 latent classes) and the best fitting model was chosen. In-depth information on statistical details can be found in Mplus references [5,6].

Effect size was calculated using Cohen's $d$ formula, i.e. difference score of intervention and control group changes compared to baseline score divided by baseline standard deviation. These values were given separately for 12 -month and 24-month effects because non-linear model for change was adopted.

A 2-sided $P$-value of $<0.05$ was considered statistically significant.

\section{Results}

At baseline, the scores in all RAND-36 scales were considerably higher in FINGER participants compared with the Finnish population of similar age (Table 1). During the 2-year intervention period, mean scores in all scales decreased in the control group, but increased in the intervention group for VT (12 months), SF (12 months), and especially GH at both 12 and 24 months. There was a statistically significant beneficial effect of intervention on the change in GH and PF at 12 and 24 months (Table 2). Effect sizes for most RAND-36 scales were small (0.02-0.08), however higher for GH (0.18-0.20; Table 2).

\section{Discussion}

In an older population at-risk of dementia, a multidomain intervention to improve or maintain cognitive functioning also had a beneficial effect on several scales of a validated HRQoL instrument, RAND-36 [3], although the effect sizes were not large. However, the net differences in GH scores were greater, between groups they were $>3$ points. This is considered clinically meaningful in RAND-36 [3] - and this difference persisted for 2 years. The effect size of GH difference was $0.18-0.20$, which is greater than that of cognitive difference $(0.13)$, primary endpoint in FINGER [1]. It is worth noting that the positive effect on GH could

Table 1

Baseline Characteristics of FINGER Participants.

\begin{tabular}{|c|c|c|c|c|}
\hline Demographic characteristics & & Intervention group ( $n=631)$ & & Control group $(n=629)$ \\
\hline Age at baseline visit, mean (SD) & & $69.5(4.6)$ & & $69.2(4.7)$ \\
\hline Proportion of women, \% & & 45 & & 47 \\
\hline Education, years, mean (SD) & & $10.0(3.4)$ & & $10.0(3.4)$ \\
\hline MMSE, points, mean (SD) & & $26.7(2.0)$ & & $26.8(2.0)$ \\
\hline $\begin{array}{l}\text { RAND-36 scales }{ }^{a} \text {, } \\
\text { age and sex-adjusted }\end{array}$ & $\begin{array}{l}\text { No. of participants with } \\
\text { measurement }\end{array}$ & Intervention group & $\begin{array}{l}\text { Control } \\
\text { group }\end{array}$ & $\begin{array}{l}\text { Age and sex-adjusted } \\
\text { population mean among } \\
\text { people aged } 65 \text { and over }{ }^{\mathrm{b}}\end{array}$ \\
\hline Physical function & 1253 & $79.0(0.8)^{\mathrm{c}}$ & $80.1(0.8)$ & 60.6 \\
\hline Role physical & 1238 & $73.1(1.4)$ & $75.7(1.4)$ & 47.0 \\
\hline Role mental & 1232 & $80.5(1.3)$ & $80.8(1.3)$ & 58.8 \\
\hline Vitality & 1242 & $71.0(0.8)$ & $71.6(0.8)$ & 60.7 \\
\hline Mental health & 1244 & $81.8(0.6)$ & $81.1(0.6)$ & 74.8 \\
\hline Social function & 1248 & $87.8(0.7)$ & $88.9(0.7)$ & 77.3 \\
\hline Bodily pain & 1249 & $74.4(0.9)$ & $74.1(0.9)$ & 64.2 \\
\hline General health & 1251 & $58.4(0.7)^{d}$ & $61.9(0.7)$ & 49.0 \\
\hline
\end{tabular}

SD: standard deviation.

a The scores of the RAND-36 scales can range from 0 (worst) to 100 (best).

b From reference [4].

c Mean (SE).

d Significantly different from control. 
Table 2

Effect of intervention on the change in RAND-36 scales from baseline to 12 and 24 months.

\begin{tabular}{|c|c|c|c|c|c|c|c|c|c|}
\hline \multirow[t]{3}{*}{ RAND-36 scales } & & \multicolumn{8}{|c|}{ Estimated mean change (intervention/control) in domains during intervention period ${ }^{a}$} \\
\hline & & \multicolumn{2}{|c|}{12 months } & \multirow{2}{*}{$\begin{array}{l}P \text {-value for } \\
\text { difference } \\
\text { between } \\
\text { groups }\end{array}$} & \multirow[t]{2}{*}{ Effect size $^{\mathrm{b}}$} & \multicolumn{2}{|l|}{24 months } & \multirow{2}{*}{$\begin{array}{l}P \text {-value for } \\
\text { difference } \\
\text { between } \\
\text { groups }\end{array}$} & \multirow{2}{*}{$\begin{array}{l}\text { Effect } \\
\text { size }\end{array}$} \\
\hline & & $\begin{array}{l}\text { Intervention } \\
\text { ( } P \text {-value for } \\
\text { change) }\end{array}$ & $\begin{array}{l}\text { Control } \\
\text { ( } P \text {-value for } \\
\text { change) }\end{array}$ & & & $\begin{array}{l}\text { Intervention } \\
\text { ( } P \text {-value for } \\
\text { change) }\end{array}$ & $\begin{array}{l}\text { Control } \\
\text { ( } P \text {-value for } \\
\text { change) }\end{array}$ & & \\
\hline Physical function & 1253 & $-1.2(0.003)$ & $-2.5(<0.001)$ & 0.045 & 0.06 & $-2.3(<0.001)$ & $-4.0(<0.001)$ & 0.013 & 0.08 \\
\hline Role physical & 1238 & $-1.6(0.27)$ & $-4.5(0.014)$ & 0.29 & 0.08 & $-1.7(0.43)$ & $-4.7(0.004)$ & 0.11 & 0.08 \\
\hline Role mental & 1232 & $-0.1(0.95)$ & $-0.9(0.51)$ & 0.57 & 0.02 & $-0.1(0.95$ & $-1.7(0.29)$ & 0.41 & 0.05 \\
\hline Vitality & 1242 & $0.7(0.20)$ & $-0.7(0.34)$ & 0.11 & 0.07 & $-0.3(0.64)$ & $-0.9(0.026)$ & 0.49 & 0.03 \\
\hline Mental health & 1244 & $-0.3(0.40)$ & $-0.3(0.48)$ & 0.97 & 0.0 & $-0.6(0.17)$ & $-0.9(0.061)$ & 0.56 & 0.02 \\
\hline Social function & 1248 & $0.5(0.38)$ & $-0.5(0.39)$ & 0.21 & 0.06 & $-0.8(0.057)$ & $-1.2(0.043$ & 0.53 & 0.02 \\
\hline Bodily pain & 1249 & $-1.3(0.07)$ & $-1.1(0.52)$ & 0.87 & 0.01 & $-2.4(0.086$ & $-2.1(0.099)$ & 0.89 & 0.01 \\
\hline General health & 1251 & $1.6(0.026)$ & $-1.8(0.004)$ & $<0.001$ & 0.20 & $1.5(0.003)$ & $-1.6(0.050)$ & $<0.001$ & 0.18 \\
\hline
\end{tabular}

${ }^{\text {a }}$ Mean values are estimated based on the growth mixture models adjusted for age, sex, education years, and points of Mini Mental State Examination (MMSE) at baseline.

b Effect size was calculated as described in Methods.

be demonstrated in the intervention group compared to the control group, even though FINGER participants had a relatively good HRQoL at baseline as compared to population standards [4]. Even though the FINGER participants were population-driven, common experience is that voluntary participants in trials may differ in various ways from non-participants [7].

The results on GH are especially interesting, because self-rated health ("self-perceived health" [SRH]), one component of the GH scale in RAND-36, has been repeatedly shown to be associated with important clinical outcomes including mortality, disability, and use of social insurance facilities and health care services [8-13], independently of conventional risk factors. Recently, SRH has also been shown to predict the development of old age frailty during long-term in clinically healthy middle-aged men [14]. SRH is considered to represent a global perception of an individual's current state of health, which is not necessarily identical with objective state of health.

Conseptualizing SRH is challenging, both biology and culture are involved [15], but among the SF-36/RAND-36 scales it is more strongly related to physical functioning than dimensions of mental health and social functioning [16]. Nevertheless, improvement in GH and SRH may also represent better stress-handling ability and coping [10]. The effects of the FINGER intervention on HRQoL therefore complement the beneficial effects of the intervention on the primary outcome, cognition, and present a potential of the multidomain intervention to improve overall health and wellbeing of older individuals.

The present results may also hint how various parts of the multidomain intervention contributed to the clinical results of the trial. Physical exercise is interesting here because PF was improved in the intervention group, and physical function is also an important determinant of SRH [16]. However, a recent systematic review could not establish evidence that aerobic physical exercise alone would have cognitive benefit in cognitively healthy older people [17]. On the other hand, in the randomized Finnish Alzheimer disease exercise trial (FINALEX) physical exercise alone improved physical function [18], but had limited effect on cognition (only executive function) in established memory disease [19]. FINGER participants differed from those studies, because their cognition was average or slightly below average and they received multidomain intervention. Forthcoming analyses of adherence during FINGER intervention period will give more data on the issue of how various components of the multidomain intervention were associated with changes in cognition.

Strengths of the present study include the randomized, controlled design, low drop-out rate, and use of generic and validated HRQoL instrument. Limitations include the small effect sizes between groups and potential presence of the regression to the mean phenomenon. Also, it is impossible to conclusively mask the study group membership in this type of study and this may affect self-reported data, such as HRQoL. Finally, long-term effects and sustainability of the beneficial effects are not known.

\section{Ethical statement}

The FINGER study is registered at Clinicaltrials.gov (NCT01041989). All participants gave informed consent and the study was approved by appropriate ethical committees.

\section{Disclosure of interest}

The authors declare that they have no competing interest.

\section{Acknowledgments}

Funding support was received from the Academy of Finland (grants 129395, 129397, 129459, 129421, 129416, 129511, 129401, 259615, 278457), MIND-AD Academy of Finland 291803 and Swedish Research Council 529-2014-7503 (EU Joint Programme - Neurodegenerative Disease Research, JPND), La Carita Foundation, Alzheimer Association, Alzheimer's Research and Prevention Foundation, Juho Vainio Foundation, Novo Nordisk Foundation, Finnish Social Insurance Institution, Ministry of Education and Culture, Salama bint Hamdan Al Nahyan Foundation, Axa Research Fund, EVO funding for University Hospitals of Kuopio, Oulu, and Turku and for Seinäjoki Central Hospital and Oulu City Hospital, Swedish Research Council, Swedish Research Council for Health, Working Life and Welfare, Stiftelse Stockholms Sjukhem, and af Jochnick Foundation.

\section{References}

[1] Ngandu T, Lehtisalo J, Solomon A, et al. A 2-year multidomain intervention of diet, exercise, cognitive training and vascular risk monitoring versus control to prevent cognitive decline in at-risk elderly people (FINGER): a randomised controlled trial. Lancet 2015:385(9984):2255-63.

[2] Haywood KL, Garratt AM, Fitzpatrick R. Quality of life in older people: a structured review of generic self-assessed health instruments. Qual Life Res 2005:14:1651-68.

[3] Hays RD, Morales LS. The RAND-36 measure of health-related quality of life. Ann Med 2001;33:350-7.

[4] Aalto AM, Aro AR, Teperi J. RAND-36 as a measure of Health-Related Quality of Life. Reliability, construct validity and reference values in the Finnish general population. Helsinki: Stakes, research Reports 101; 1999.

[5] Muthén LK, Muthén BO. Mplus User’s Guide, 5th ed., 2011.

[6] Muthén B. Second-generation structural equation modeling with a combination of categorical and continuous latent variables: New opportunities for latent class/latent growth modeling. In: Collins LM, Sayer A, editors. New methods for the analysis of change. 2001. p. 291-322. 
[7] Hughes-Morley A, Young B, Hempel RJ, Russell IT, Waheed W, Bower P. What can we learn from trial decliners about improving recruitment? Qualitative study. Trials 2016;17:494.

[8] Idler EL, Benyamini Y. Self-rated health: self-rated health and mortality: a review of twenty-seven community studies. J Health Soc Behav 1997;38: 21-37.

[9] Giltay EJ, Vollaard AM, Kromhout D. Self-rated health and physician-rated health as independent predictors of mortality in elderly men. Age Ageing 2012;41:165-71.

[10] Bopp M, Braun J, Gutzwiller F, Faeh D. Health risk or resource? Gradual and independent association between self-rated health and mortality persists over 30 years. PLoS One 2012;7:e30795 [electronic resource].

[11] Wu S, Wang R, Zhao Y, et al. The relationship between self-rated health and objective health status: a population-based study. BMC Public Health 2013; $13: 320$.

[12] Stenholm S, Pentti J, Kawachi I, Westerlund H, Kivimaki M, Vahtera J. Self-rated health in the last 12 years of life compared to matched surviving controls: the health and retirement study. PLoS One 2014;9:e107879 [electronic resource].

[13] Halford C, Wallman T, Welin L, et al. Effects of self-rated health on sick leave, disability pension, hospital admissions and mortality. A population-based longitudinal study of nearly 15,000 observations among Swedish women and men. BMC Public Health 2012;12:1103.
[14] Huohvanainen E, Strandberg AY, Stenholm S, Pitkälä KH, Tilvis RS, Strandberg TE. Association of self-rated health in midlife with mortality and old age frailty: a 26-year follow-up of initially healthy men. J Gerontol A Biol Sci Med Sci 2016;71:923-8.

[15] Jylha M. What is self-rated health and why does it predict mortality? Towards a unified conceptual model. Soc Sci Med 2009;69:307-16.

[16] Mavaddat N, Kinmonth AL, Sanderson S, Surtees P, Bingham S, Khaw KT. What determines self-rated health (SRH)? A cross-sectional study of SF-36 health domains in the EPIC-Norfolk cohort. J Epidemiol Comm Health 2011;65:800-6.

[17] Young J, Angevaren M, Rusted J, Tabet N. Aerobic exercise to improve cognitive function in older people without known cognitive impairment. Cochrane Database Syst Rev 2015:4:CD005381. 14651858.CD005381.pub4.

[18] Pitkälä KH, Pöysti MM, Laakkonen ML, et al. Effects of the Finnish Alzheimer disease exercise trial (FINALEX): a randomized controlled trial. JAMA Intern Med 2013;173:894-901.

[19] Öhman H, Savikko N, Strandberg T, et al. Effects of exercise on functional performance and fall rate in subjects with mild or advanced Alzheimer's disease: secondary analyses of a randomized controlled study. Dement Geriatr Cogn Disord 2016;41:233-4. 